\title{
Study on Wei Shijian Cucurbit Flute Music
}

\author{
Hongfei Liu \\ College of Music, Hubei Engineering University, Xiaogan Hubei, 432000, China
}

Key words: Wei Shijian, Cucurbit flute, Cucurbit flute music.

\begin{abstract}
Wei Shijian is one of the outstanding performers of cucurbit flute music. He has been devoting himself into culture promotion, theoretical research, teaching, performing, and creation of cucurbit flute music, and has made great contribution to the development of folk music. This paper is intended to systematically research Wei Shijian's cucurbit flute music compositions, with a hope to let more people understanding Wei Shijian's cucurbit flute music and inherit cucurbit flute music culture.
\end{abstract}

\section{Introduction}

Wei Shijian is a famous Chinese cucurbit flute music composer and educator, a member of China Artistic Association, a member of China Nationalities Orchestra Society Cucurbit Flute Bau Professions Council, and the chief editor of the editorial department of Cucurbit Flute Forum. He has been loving ardently music since the times of middle school, and is good at bamboo flute, flute, stringed instrument music, keyboard instrument and musical creation. Graduated from Liaocheng Normal University as a music major in 1980, he has been working on music education as long as more than 30 years. He is a well-know cucurbit flute artistic culture promoter. His cucurbit flute music compositions are of novel themes, which were created by adapting folktales and folklores in a narrative way. His compositions all are novel and unique, which can be said to be of fine quality. His compositions are of novel structure, clear layer, and distinct theme; the composition of periods is well managed, full of ups and downs, and well structured. Proper keynote and material are selected to embody rich regional characteristics, and show graceful, smooth and magnificent melodies. Concerning layout, he is good at taking advantage of western and Chinese instruments, giving full play to orchestral music that is rough and intense to drive atmosphere, and making full use of percussion instruments to enhance the emotional mood, to make the respective advantages of lead and harmony instruments complementary to each other, and perfect his compositions and performance. His pioneering spirit and creative achievements further prove that cucurbit flute is advancing to be professional, scientific, and modern, and consolidate the important position of cucurbit flute in folk music. This paper is intended to discuss the style of cucurbit flute music creation and his contributions via case study of compositions in the album titled Cucurbit in Blossom. 
Wei Shijian Cucurbit Flute Music Introduction

The compositions in the Cucurbit in Blossom are as follows:

\begin{tabular}{|c|c|c|c|}
\hline Creation Time & Title & Genre & Remarks \\
\hline October 27, 2010 & Huang He Lian & Concerto & \\
\hline October 2010 & Ma Lan Hua & Ballade & \\
\hline October 25, 2010 & Lady Meng Jiang & Concerto & \\
\hline May 2010 & Tibetan Incense & Solo & \\
\hline April 21, 2010 & Great Love & Solo & \\
\hline 2010 & North Henan Ditty & Solo & \\
\hline January 2010 & Dreamy Liujiang & Solo & \\
\hline April 2010 & Little Sister & Solo & “Cucurbit Trilogy” I \\
\hline November 3, 2010 & $\begin{array}{c}\text { Fine Rain in Southern } \\
\text { Anhui }\end{array}$ & Solo & \\
\hline October 28, 2010 & Love & Solo & “Cucurbit Trilogy” II \\
\hline 2009 & Red Leaf & Solo & $\begin{array}{l}\text { Rank 6th in the } 2009 \\
\text { National "Lakeshore Cup” } \\
\text { Cucurbit Flute Original } \\
\text { Works Competition }\end{array}$ \\
\hline April 12, 2010 & Red Kapok & Solo & \\
\hline August 2010 & Little Girl & Solo & “Cucurbit Trilogy” III \\
\hline April 2010 & Hu Sa-Wo Luo Festival & Solo & \\
\hline November 6, 2010 & Ancient Town Caprice & Solo & \\
\hline
\end{tabular}

Wei Shijian's cucurbit flute compositions are mainly folk music, and have vitality of modern music. He shows us stereo musical poets and paintings with folktales and folklores as theme by various means of artistic expression. The Huang He Lian was created with western music material as the keynote, taking the Yellow River to symbolize the unyielding heroism of Chinese nation, and depicting the Yellow River rolling ahead ceaselessly and nourishing people on both sides; Ma Lan Hua is a composition of the style of prairie, which was created according to the romanticism between $\mathrm{Ma}$ and Xiaolan on the prairie. Dolorous horse head string instrument, broad piano, elegant violin, and rhythm and metre of sleigh bells and wooden fish are employed to background cucurbit flute. This composition is performed by means of vocal music and duet, and consists of eight periods. The Lady Meng Jiang was created according to the thrilling story of "Lady Meng Jiang bringing down the Great Wall with tears”. In the composition, the musical elements of a Jiangsu folk song titled Lady Meng Jiang Bringing Down the Great Wall with Tears and a Hebei folk song titled Xiao Bai Cai are applied, making it full of folk characteristics. The Tibetan Incense is a cucurbit flute solo with Buddhist characteristics, in which a phrase of "653" repeats to indicate the antiquity of Tibet and the heaviness of history. The Great Love shows a weepy scene where Chinese people pull together and go through thick and thin together in face of overwhelming natural disasters. The North Henan Ditty 
is a circuit flute opusculum of typical music style created according to the melody of Henan Opera. The Dreamy Liujiang was created in memory of Liu Sanjie, which is of typical Zhuang's folk song style and deepens people's profound memory of Liu Sanjie. The Little Sister was created based on the Kangding Love Song, in which the ingenious application of glide and staccato makes it vivacious and light-hearted. The Fine Rain in Southern Anhui is of the style of Huangmei opera. The Love is of concise material and vivid rhythm, is romantic and modern, and is suitable for dancing. The Red Leaf depicts the prosperous life and joy of peasant families by the aid of natural beautiful sceneries all over the mountains and plains. The Red Kapok shows the unyielding heroism and fierce resistance of the red army. The blood red kapoks are like smiling faces of the soldiers, who deserve our highest consideration, respect and compliment. For the Little Girl, the tone of a folk song titled "Flower" is absorbed to shape the personalities and positive attitude of the little girl. The Hu Sa-Wo Luo Festival depicts Achang girls and boys in Husa of Luxi in the border area of Yunnan can sing and dance well, and are infatuated with intoxicating cucurbit flute. In the Ancient Town Caprice, the elements of Hebei Bangzi opera and Datang music are applied, leaving an infinite space of pondering.

\section{Innovation in Wei Shijian's Cucurbit Flute Music Compositions}

Wei Shijian, drawing lessons from Wang Houchen and Li Chunhua's compositions, and rooting in folk music, shows the creation characteristics of modern music vitality. He is good at creation themed by folktales and folklores with various means of artistic expression, to show stereo music poets and paintings to us.

\section{Innovation of Theme}

He takes melodies of different sentimental colors as the keynote, and adopts modern means of artistic expression, to embody the strong regional characteristics and present elegant, smooth and magnificent melodies.

Take the example of the Tibetan Incense. Different from traditional cucurbit flute music, the Tibetan Incense is a cucurbit flute solo with Buddhist characteristics. The solemn, respectful and mysterious Tibet is incisively and vividly showed via cucurbit flute music, making audiences feel like that they are in it. The $5 \sim 12$ bars in the first paragraph imitate the sound of chanting, making audiences feel like that they see groups of Tibetans going back and forth. The composition shows us a vivid scene (see Notation 1):

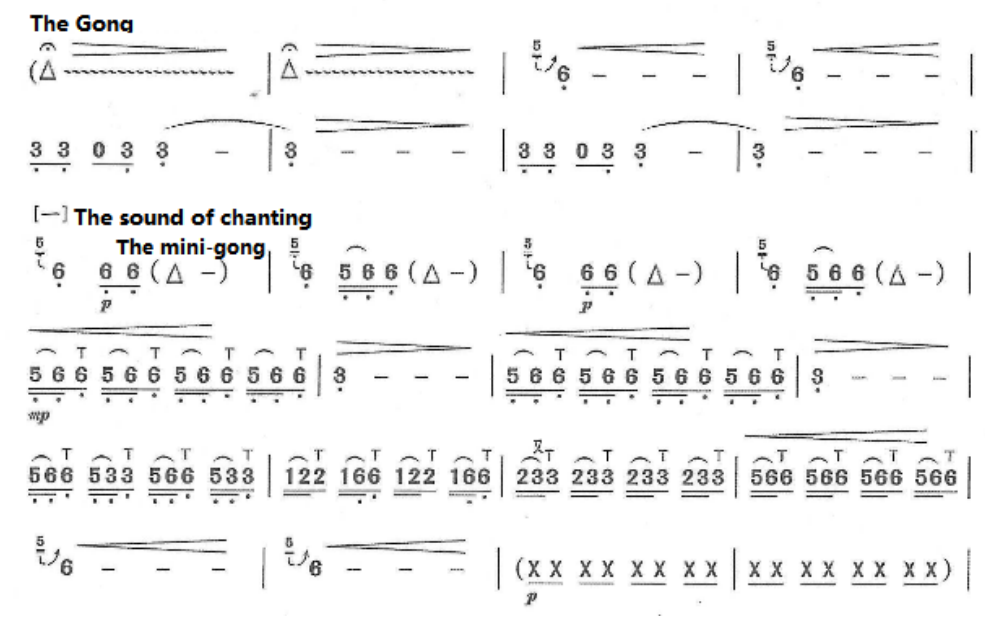

Notation 1

The second period is for croon with male voice. The calm and solemn rhythm also seems to contain some suppression feeling left by the history, and Tibetans moral integrity and dignity. The third period is about pious praying, gives prominence to female characteristics. In this period, emphasis is laid on flexibility and purity, and no distracting thought is found. The first three periods 
are for foreshadowing, and the fourth period stands out in a sudden, like the shining sun that gives a bright feeling to audiences and makes audiences feel like seeing auspicious clouds above the head. In the fifth period, the emotion is released to the extreme, which is majestic and powerful, and shocks audiences. The sixth period leads us to a dreamworld along the incense cloud, which is presented with virtual technique and brings a soul dream round. The last sentence fades out to end, leaving a space for imagination......

The Fine Rain in Southern Anhui was created based on Huangmei ditty, so it is of the style of Huangmei opera. The first period (1-18 sections) is as shown in Notation 2:

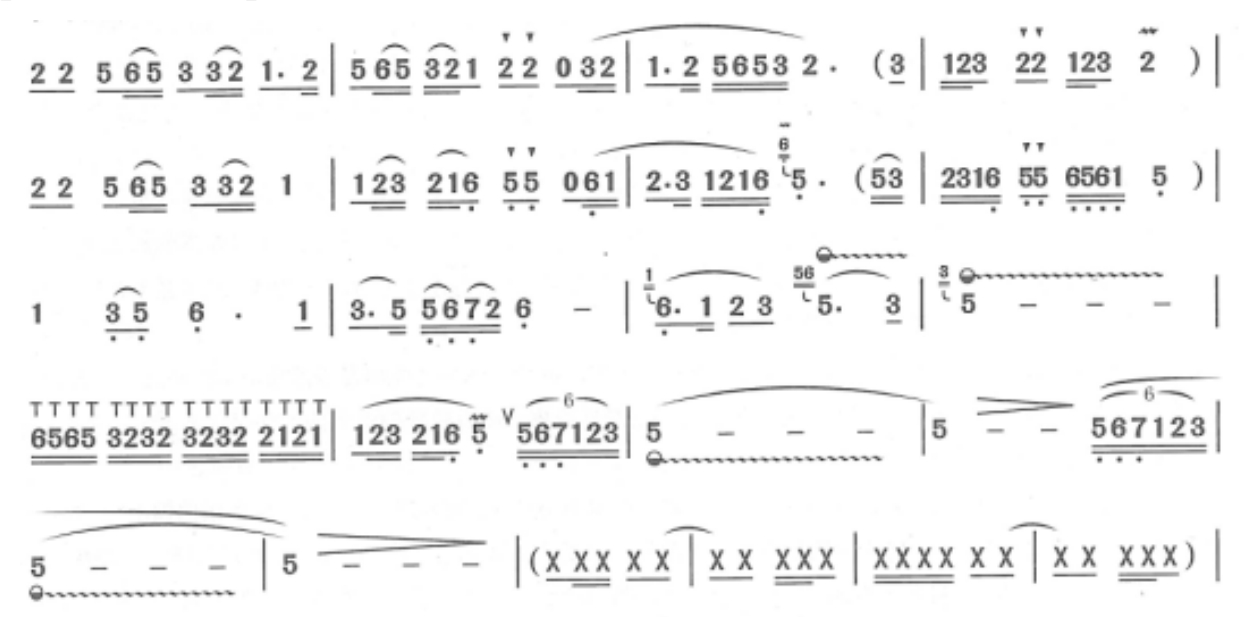

Notation 2

It is about raining scene. It depicts a beautiful scenery of apricot blossoms and spring shower moistening the regions south of the Yangtze River, and reflects the characteristics of spring persistent rains in the regions south of the Yangtze River. The second period (19-34 sections) is about playing in the continuous patter of raindrops. Especially, the 27th to 34th sections reflect the characteristics of spring rain, fine rain. The 35th to 50th sections show embellishment in the rain-people. People with oiled paper umbrellas run in the meadow to enjoy the fine spring rain. The 51th to 68th sections represent the scene in the 19th to 34th sections. It still shows the continuous patter of raindrops, and many people with oiled paper umbrella receiving the gift of nature-rain (see Notation 3):

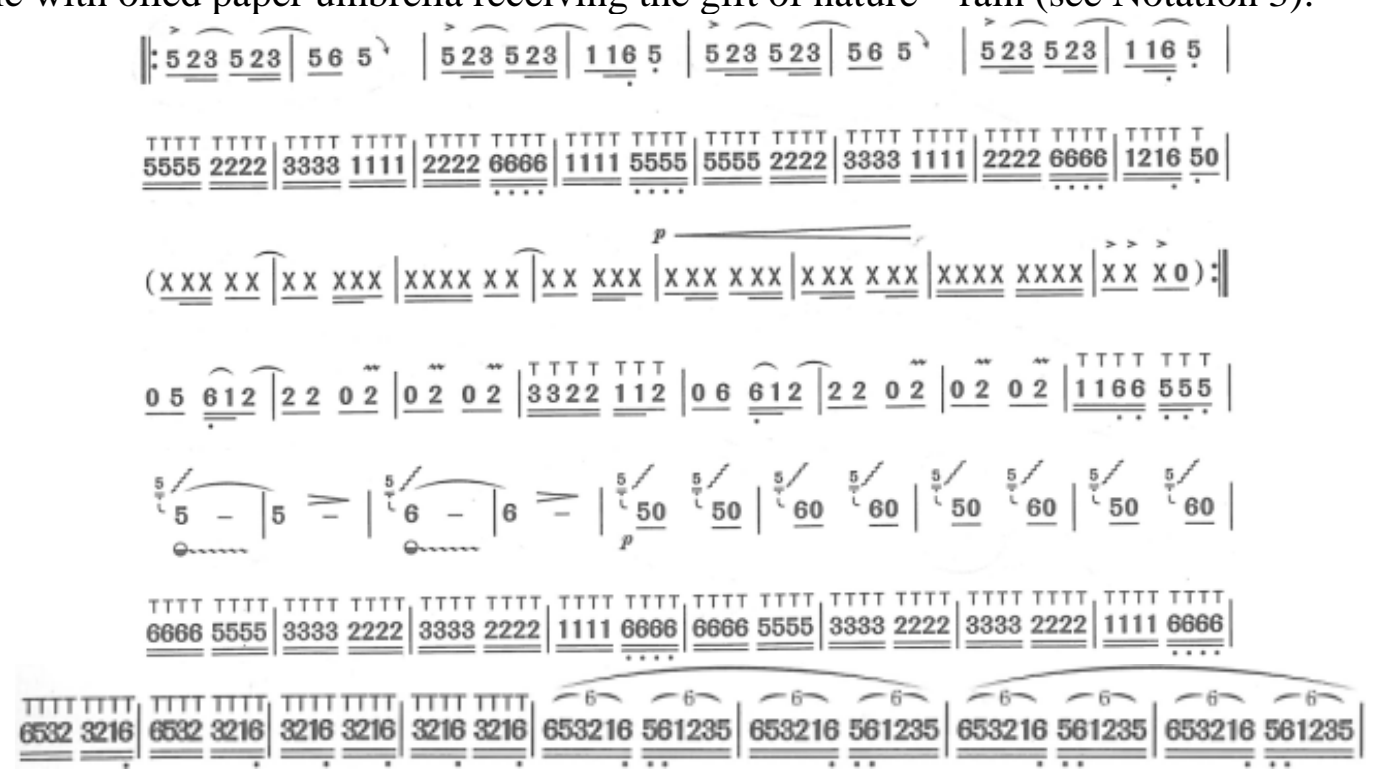

Notation 3

The third period (69 to 90sections) is for praising rain. The ebullient melody presents a beautiful spring full of happiness. The fourth period (91-101 sections) represents the beautiful scenery of 
apricot blossoms and spring shower moistening the regions south of the Yangtze River. Every thing is beautiful as always. End: 102 to the end. The spring rain still doesn't stop, and is like gauze, fog, smoke and dust. (see Notation 4):

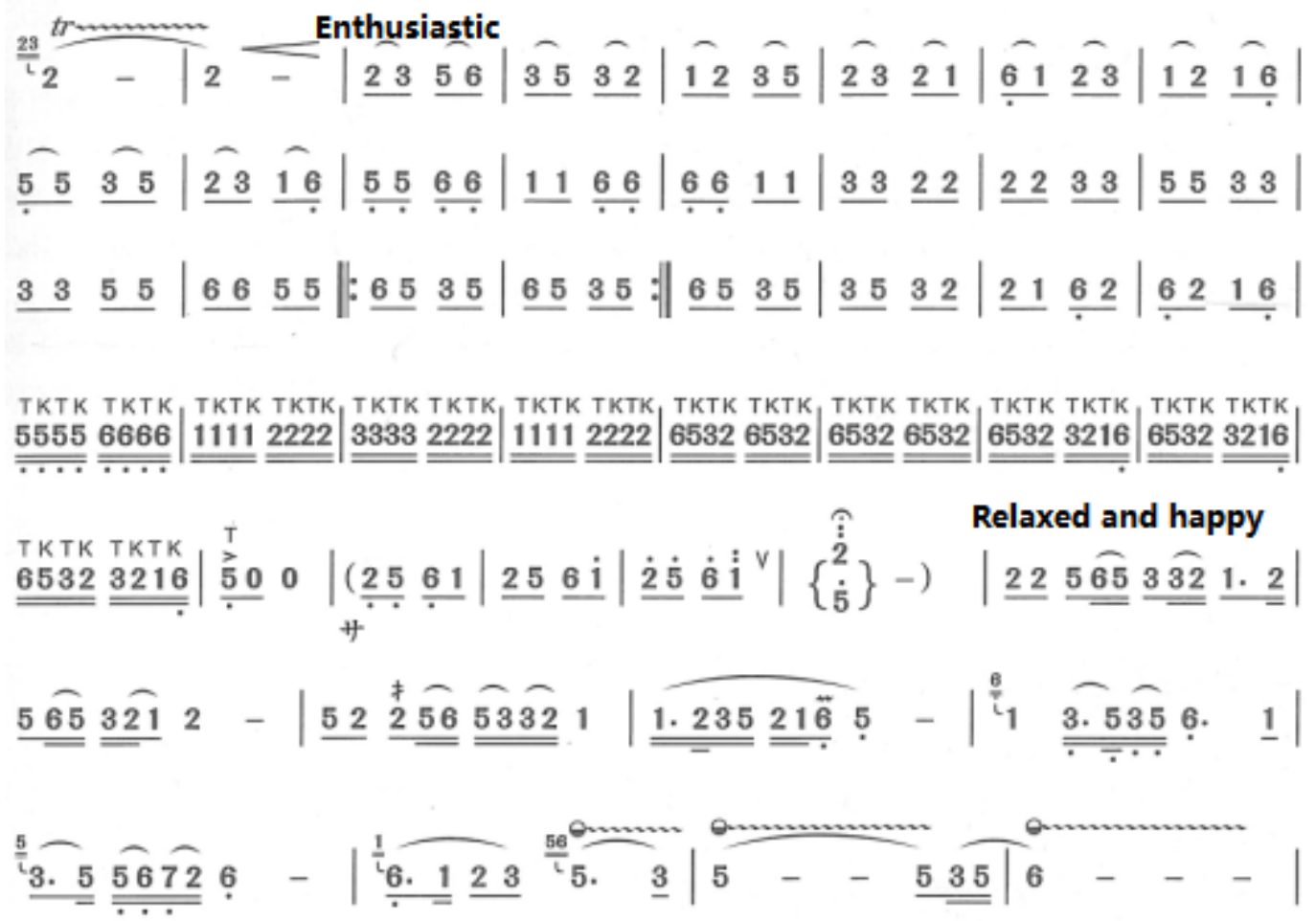

Light and wonderful

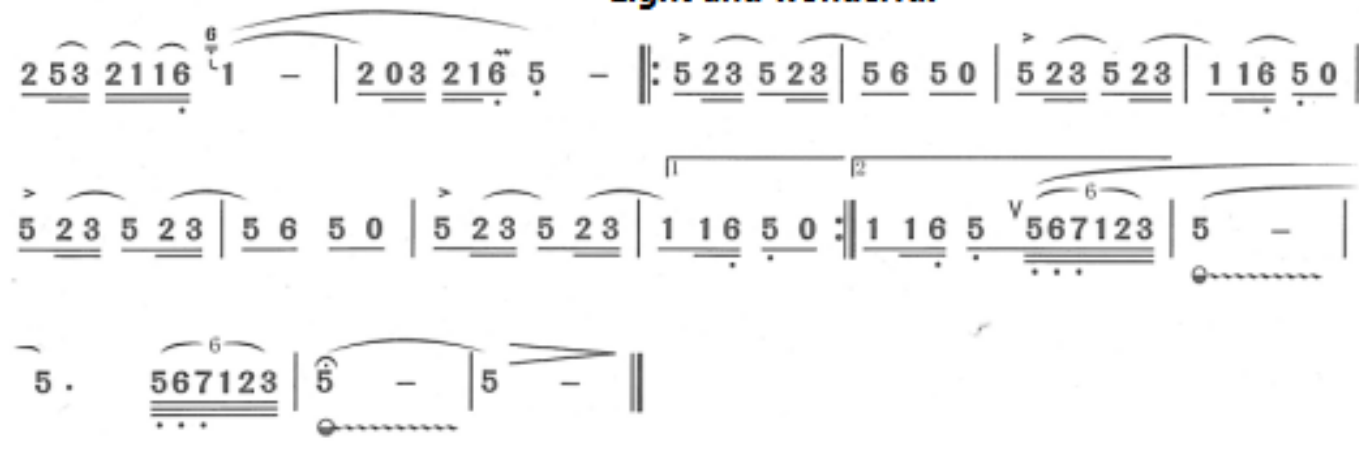

Notation 4

\section{Innovation of Genre}

Performing concerto with cucurbit flute is another breakthrough in the field of cucurbit flute music creation, and a new chapter in the development history of cucurbit flute.

The difficulty of narrating a story with a pipe instrument - cucurbit flute doesn't rest in the creation of melody, but in stylistic shift. He has integrated traditional music and modern music are integrated together, and incisively and vividly shows the emotion and keynote of the whole composition by means of vocal music, modulation and harmony. The Lady Meng Jiang is a large concerto, which is of a musical structure constituted by the first principal part (exposition), the second accessory part (comparison), the development, and the theme representation. Since the composition is long, it is easy to become boring. Therefore, vocal music is added in the exposition to sum up the theme, to give a new auditory feeling to audiences.

The Huang He Lian is the second cucurbit flute concerto of Wei Shijian, following the Lady Meng Jiang. This composition is original in conception, of clear layer and with distinct theme; the composition of periods is well managed, full of ups and downs, and well structured. Proper keynote 
and material are selected to embody rich regional characteristics, and show graceful, smooth and magnificent melodies. Concerning harmony layout, he is good at taking advantage of western and Chinese instruments, giving full play to orchestral music that is rough and intense to drive atmosphere, and making full use of percussion instruments to enhance the emotional mood, to make the respective advantages of lead and harmony instruments complementary to each other, and perfect his compositions and performance. Concerning the creative approach, he can appropriately apply the multimode structure and the modulation of cucurbit flute to bring the functions, lingering charm and tensity of lead instruments into full play to achieve an effect of an integral whole. The composition is closely linked, is poetic and picturesque, full of ups and downs, and is unusually brilliant. The magnificent mother river rolls from a distance, roaring waves and flowing down vigorously. After "a night of rains and winds", the fertile soil on both sides acquires a completely new outlook. Suddenly, winds and storms come, danger and disaster are approaching, and the Yellow River makes mournful sounds and bursts into tears. We seem to hear the Yellow River is roaring, growling, and summoning her children! We see men by the sides of the Yellow River rise, full of power and grandeur! Their firm and unyielding eyes, and manhood of fighting the nature frighten heaven, move the earth, make the gods cry, and heat up people! The composer's inventive mind is embodied better in the period of climax of "Huang He Lian". The lead, accompany and vocal music are so harmony with each other to sound fair-sounding melody full of graceful and soulful lingering charm, as if sincere children are pouring out their heart to their great mother. It is touching. Especially the wordless singing is of great power and penetrating power. No word is even needed to express the Chinese descendants' infinite praise and attachment to the mother river, the Yellow River.

\section{Innovation of Creative Techniques}

In the Huang He Lian, the sixth period (bringing down the Great Wall with tears) is presented by means of modulation (from G to D), to adjust the lingering charm. For the whole composition, accompany of certain proportion is adopted, having broadened the range, deepened the sentiment, and making the whole composition of stronger expressive force and power. For the composition, the materials from a Jiangsu folk song titled "Lady Meng Jiang Bringing Down the Great Wall with Tears” and a Hebei folk song titled "Xiao Bai Cai” are applied. Meanwhile, to avoid obsolete tone, modern musical elements and composition techniques are applied on a large scale, with a hope to realize organic combination of "tradition" and "modern”. Stringed instruments, wind instruments and percussion instruments are employed to background the effect and atmosphere of cucurbit flute, which is shocking.

The Tibetan Incense is a composition emphasizing harmonization between circuit flute and accompany. For performance of this composition, attention should be paid to managing role transition to fall into a state of forgetting self. Only in this way, the composition can be performed well. Secondly, the two unities of opposites should be handled well. (1) The musical materials of the first, second and third periods and the end are of strong style of Buddhist music and are in line with each other. (2) The musical materials of the fourth, fifth and sixth periods are emotional and about transition from "static state” to "dynamic state”, of which the style is apparently different from others'. This should be fully showed via feeling and performance practices. Lastly, the characteristics of performance Buddhist music should be grasped. Buddhist music is in a solemn atmosphere, calm and quiet, and pure. Performers should feel that they are in an intangible world, regard every structure and period as chanting, and not modify them deliberately but reveal musical language in a natural way. Wei Shijian is a productive composer, and his compositions all are novel and unique, which can be said to be of fine quality. His large cucurbit flute concerto-Huang He Lian is a revolution in the history of cucurbit flute music creation, and a large challenge to the future development of cucurbit flute art. People always regard cucurbit flute as a "toy", think it can be used to perform some ditty or opusculum, and even consider it to be a weird folk music instrument. The Huang He Lian tells us that cucurbit flute is a tongue for performing folk music, and it can be used to perform compositions of different styles and performing concerto, ballad, caprice, and other large compositions, and is of a 
unique style. His pioneering spirit and creative achievements further prove that cucurbit flute is advancing to be professional, scientific, and modern, and consolidate the important position of cucurbit flute in folk music. The Cucurbit in Blossom is his first album of original works. And his other works also have the characteristics stated above.

He is crazy about folk music, and has been devoting himself in cucurbit flute culture promotion, theoretical research, teaching, performance and music creation, having made a great contribution to the development of folk music. We should follow the example of him to do our best to contribute to the development of cucurbit flute.

\section{References}

[1] Wei Shijian, Chinese Cucurbit Flute Performance Scheme, Beijing: Published by New World Press, 2010.

[2] Wei Shijian, Cucurbit In Blossom, Jinan: Published by Qilu Electronic Audio \& Video Publishing House, 2011. 